\title{
Utilization of the Haddon Matrix to Organize Factors of Survived Accidental Residential Fires: Frequencies for Human, Agent, and Environment-related Variables
}

\author{
LIN XIONG ${ }^{1,2}$, MICHELLE BALL ${ }^{1,2}$ AND DOROTHY BRUCK ${ }^{1,2}$ \\ ${ }^{1}$ Discipline of Psychology, College of Arts, Victoria University, Melbourne, Australia \\ ${ }^{2}$ Centre for Environmental Safety and Risk Engineering, Victoria University, Melbourne, Australia \\ Building 3N, St Albans campus, Victoria University, VIC 3021, Australia
}

\begin{abstract}
Drawing upon interviews of 183 people who have survived accidental residential fires, this study adopted the basic concepts (human, agent, environment) of the Haddon Matrix to organize factors associated with survived accidental residential fires where there was no fire death or serious injury with extended hospitalization involved. Human activities during a fire were also identified, including how people first alerted to the presence of a fire and how they attempted to extinguish a fire. Electrical failure and unattended cooking were found to be the leading causes of survived fires. Kitchens and bedrooms were reported as the main rooms of fire origin. The study revealed four important new findings. These new findings are: 1) people's knowledge of fire safety and awareness of unsafe fire behaviours was extremely limited; 2) an overwhelming majority of hosts had previous fire experiences at the time of the survey; 3 ) risk factors that are documented elsewhere to be highly related to fire fatalities were found not to be closely related to survived fires, such as alcohol, drugs, smoking, and being asleep; and 4) the majority of hosts took proactive actions when facing a fire, such as calling fire brigade, attempting to extinguish a fire, and trying to alert others. The Haddon Matrix was found to be a useful tool for organizing a wide range of relevant accidental residential fire variables, with the current paper presenting important new information about the frequencies of such variables where no fire death or serious injury has occurred.
\end{abstract}

KEYWORDS: survived accidental residential fires, human factors, environment, fire agent, the Haddon Matrix

\section{INTRODUCTION}

A review of the literature suggests that studies of factors associated with residential fires have so far focused predominantly on the risks of death [2-4]. Although it is widely known that survived residential fires are the most prevalent fires and are an important public safety issue, there has been very little work done in the area of survived residential fires [5], particularly, where no serious injury was involved. Yet some research suggests there are significant differences between fatal and survived fires. For example, fatal fires were more likely to have been caused by smoking, with adults over 50 years of age being at the highest risk $[4,6]$. By contrast, cooking has historically found to be the leading cause of most survived fires, in particular those that were extinguished without fire department assistance, and people aged 20-34 are twice as likely to be injured than the general public of all other ages [4, 7]. These etiological differences between fatal and survived fires motivated the design of this study that aims to utilize the key concepts, human-agent-environment, of the Haddon Matrix to clearly organise relevant factors (e.g. demographics, ignition, property type) of survived accidental residential fires (where there was no death or serious injury with extended hospitalization involved) and consider their prevalence within the sample.

This paper extends the existing literature in three salient ways. First, this study enriches the current understanding of residential fires by focusing on people who have survived with no serious injuries, an area that has been largely ignored in the past. Survived fires with no death and less serious injuries are the most prevalent fires and cause substantial property damage, financial loss, and negative psychological effects (i.e., distress) to fire victims. To effectively minimize the frequency and consequences of such fire incidents and prevent the possible occurrence of potential disasters with more serious outcomes (i.e., fire death and serious injuries), investigations surrounding contributing factors of survived fires are important. Second, this study advances the current fire theory building process by adopting the basic concepts (i.e. human, agent, environment) of the Haddon Matrix $[8,9]$ to organise factors associated with residential fires. The Haddon Matrix has been viewed as one of the most widely used paradigms in the injury and death prevention area $[10,11]$. The utilization of this matrix provides an organisational tool to facilitate a 
comprehensive understanding of the complex circumstances surrounding a residential fire. It allows the organisation of factors by different phases (human, agent, and environment) and the sequence of the event (pre-event, event, and post-event). Third, this study extends the existing knowledge of human behaviour in fire by considering such issues as awareness of the presence of a fire, any attempt at extinguishing fire, and finally the methods of fire extinguishment.

\section{RESEARCH QUESTION AND OBJECTIVES}

One research question informs this study: what are the nature and characteristics of survived accidental residential fires where there was no fire death or serious injury with extended hospitalization involved? In order to answer this question, this paper aims to describe the nature of survived accidental residential fires by applying the key concepts of the Haddon Matrix to accommodate possible factors within human, agent, and environment contexts and present their frequencies. Factors examined were adopted from previous studies of residential fires.

\section{THE HADDON MATRIX}

The Haddon Matrix was developed by Dr William Haddon Jr, a leader in highway accident research and prevention, over four decades ago. His matrix of three columns (human, agent, environment) and three rows (pre-event, event, post-event) combined public health concepts as targets of change. Since that time, the Haddon Matrix has been widely adopted as a tool to identify risks related to an injury or death and in so doing, to develop effective strategies to reduce the likelihood of disasters occurring and to minimize the consequences when they do occur [10-12]. Over a decade ago Rhodes and Reinholtd [13] first introduced the basic principles of the Haddon Matrix to fire research. These authors argued that research attention should shift from traditional focus on fire service response, suppression, and technological solutions to activities that address the human dimension associated with fatal fires, and highlight the vulnerability of high risk groups. While their paper made a significant contribution, the number of both factors examined and fire fatalities involved $(\mathrm{n}=66)$ was relatively limited.

Drawing upon the Haddon Matrix, the Rhodes and Reinholtd [13] study and previous studies of residential fires $[1,3,14-16]$, this paper accommodated a variety of factors of residential fires within human, agent, and environment contexts, as shown in Figure 1. The 'human-related factors' section captures many aspects of a fire victim, including behaviour and condition, and involvement in the fire start. The 'fire agent' section refers to factors that take an active role in a fire or produce a specified effect, for example ignition factor. The 'environment' section covers the information associated with the physical and social environment of a building where fires occurred.

\section{MATERIALS AND METHODS}

This study draws upon the data from the Victoria University Residential Fire Survivors' Database (referred to below as the Survivors' Database). The data collection procedures for this database involved three stages: the referral; interview; and data coding and entry.

The referral. Referrals were provided from fire agencies in Victoria, Australia, including the Metropolitan Fire Brigade (MFB) and Country Fire Authority (CFA). These were drawn from their daily records of fire incidents. Fires were followed up if they met the following four criteria:

1) The fire must have been residential. Backyard/frontyard fires were only included if they involved a structure such as a garage or shed.

2) The fire must have been accidental. No cases where arson or serious criminal behaviour was suspected or proven were included.

3) The fire must not have involved serious injury with extended hospitalisation or death, and

4) The report from the fire agency must have suggested that fire and/or smoke had caused significant damage to the room of fire origin and/or dwelling. 


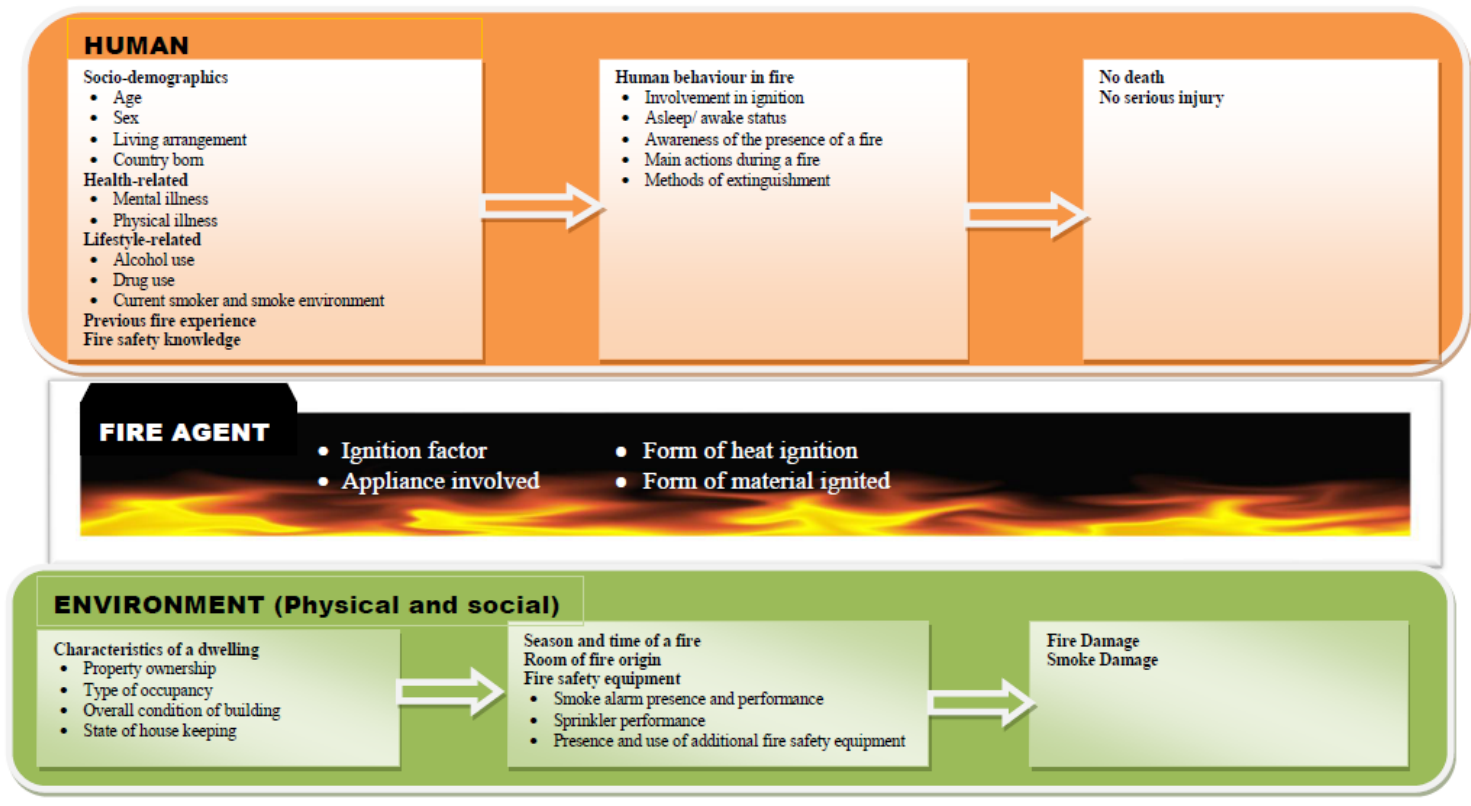

Figure 1. Factors from survived fires organized in the Haddon Matrix

Information was received from the MFB about residential fire incidents from June 2010 to December 2011 and approximately $53 \%$ of all the initial fire incidents that were assessed met the above inclusion criteria. For each eligible incident the Project Officer contacted a potential adult interviewee by phone where possible. This potential interviewee was the person most closely involved in the fire start, detection or who had called the fire brigade. Thirty percent of the potential interviewees were not contactable by phone or letter (If the Project Officer was not able to contact a potential interviewee for a fire incident by phone after three attempts, this fire incident was defined as 'not contactable'). Decline rates were quite low at about $17 \%$, and were mostly because the contacted interviewee indicated that he or she had a language barrier to deal with an interview. Finally, 128 interviews from 128 fire incidents attended by MFB were obtained, one interview per fire. A slightly different procedure was used for fire incidents within the CFA jurisdiction. A CFA Fire Officer examined the fire incident reports from January 2012 to June 2012 for areas within about $200 \mathrm{~km}$ of Melbourne, contacted potential interviewees, and then passed on the names and contact details of people who expressed interest in the project from 153 fire incidents. Full interviews were obtained from 68 of these incidents $(44 \%)$, one interview per fire. In total, 196 interviews were conducted for this study.

Interview. Interviews were normally conducted at the interviewee's home, typically where the fire had occurred. All interviews were audio-taped. The interview was designed both to make the interviewee feel comfortable and to elicit the information relevant to the variables required for the database. A specific interview structure was not imposed as it was recognised that consenting participants will want to 'tell their story' about the fire event, and it was expected that this would occupy most of the first part of the interview. Information that was not yielded by the invitation to tell their story in depth was obtained using sensitively framed questions that were based on the coding manual for this project, as discussed below.

Data coding and entry. The Survivors' Database manual was developed on the basis of the Victoria University Coronial Fire Fatality Database (referred to below as the Coroners' Database) to record information about survived fires. The codes used in the Coroners' Database manual were partially based (wherever applicable) on the US National Fire Incident Reporting System, but overall the coding process and manual are much more ambitious in scope. Further details about the Coroners' Database are published elsewhere [1]. The parameters and codes for the Survivors' Database manual were developed to correspond as closely as possible to the Coroners' Database manual. Extra codes relevant to survival in the fire and/or available from interviews with survivors were also created, such as previous fire safety 
knowledge and fire incidents, awareness of a fire, and activities during fire. The 196 interviews were coded and entered into an SPSS file, which formed the Survivors' Database.

Host. Obviously not every fire incident was started directly by human behaviour. Nor was every contactable interviewee involved in fire ignition. While the terminology may not be ideal, this paper utilizes the term of 'host' to refer to the person who was most closely involved in the fire start, detection, or who first called the fire brigade. In the case of a fire that was clearly known to have been caused directly by human actions, for example, a fire that was caused by a person placing combustible furniture directly on top of an electrical cord, this person was called the 'host' and coded as 'involved in the ignition'. By contrast, in the case of a fire that was not caused by human direct actions, for instance by electrical failure of house appliances (i.e., electrical wiring, extraction fan, central heating unit, dryer), the host is the person who first detected fire and/or first called the fire brigade and/or was interviewed. This person, however, was coded as 'not involved in the ignition'. Clearly, the host was usually, but not exclusively, the interviewee. This paper acknowledges the important role of human involvement in fire ignition and differences between fires that were caused by human direct actions and those where no direct human action was involved in the fire ignition. Deeper investigation of these differences however, is beyond the scope of the current paper.

Ethical consideration. The study was approved by the institution's Human Research Ethics Committee.

Statistical techniques. This paper will present the frequencies of variables (Figure 1) related to survived accidental residential fires and organize them according to the principles of the Haddon Matrix: human, agent, and environment.

\section{RESULTS}

As stated above, in total, 196 interviews were conducted (one host per fire). Nine interviews were later excluded because of a large percentage of missing data concerning the host. Of the 187 remaining fires, four incidents were known to have been caused directly by human actions, but it was impossible to determine who started the fire and thus these were also excluded. These four fires were two party fires caused by discarded cigarettes, and two Halloween party fires caused by candles. Finally, information concerning 183 accidental residential fires was collected for the current analysis. Differences commonly occur in the number of cases across variables owing to information that was missing or not applicable to all cases. The following sections report the frequencies of variables in human, fire agent, and environment order.

\section{Human-related factors}

Human-related factors covers information associated with socio-demographics, health-related, lifestylerelated, previous fire experiences, and fire safe knowledge. Table 1 shows the frequencies of these variables.

Socio-demographics. Given the nature of this study, the overwhelming majority of hosts were adults (over 18 years of age). Almost all hosts who were under 18 years of age $(n=18)$ were involved in the ignition. One exception was a 17 year old boy who was interviewed with his mother's consent for a fire that was caused by electrical failure, because at the time of the fire he was alone at home. The sample consisted of $45.9 \%$ males and $54.1 \%$ females and only one out of ten survived hosts reported that they were living alone at the time of fire. About one third of survived hosts $(31.9 \%, 51 / 160)$ were born overseas. Comparison with census data infers that the overseas-born hosts in this sample may be slightly overrepresented. The 2011 Australian national census data reports that at June 2011,27\% of the estimated Australian resident population were born overseas (6.0 million people) [17].

Health-related. A small group of survivors $(16.3 \%, 27 / 166)$ self-reported a diagnosed mental illness, with depression $(40.7 \%, 11 / 27)$ being the leading type of mental illness. Similarly, only a small proportion of hosts $(15.8 \%, 26 / 165)$ reported a pre-existing physical illness.

Lifestyle-related. Lifestyle-related factors examined in this study include smoking, drug and alcohol consuming behaviours as numerous evidence has shown that these three behaviours are associated closely with the heightened risks of dying in a residential fire [1,3]. Results revealed that one out of ten survived hosts reported that he or she had consumed a small amount of alcohol (i.e., one or two bottles of beer) at 
the time of fire. Only three people admitted that drugs (marijuana in all cases) had been taken at the time of fire. Over a quarter of hosts reported to be a current smoker. In over one third $(37.1 \%, 65 / 175)$ of households where fires occurred, another person who was living with the host at the time of a fire was reported as a current smoker. Smoking was permitted inside the home in 20.9\% (36/172) of households.

Previous fire experiences and fire safety knowledge. An overwhelming majority of hosts reported that they had previously experienced fire incidents. Only $7.2 \%$ of hosts reported that they had no pre-existing knowledge about fire safety. Another $69.9 \%$ of hosts had only basic and/or general knowledge of fire safety and the remaining one third of hosts reported some specific learning (i.e., workplace learning) or technical/ formal training in terms of fire safety.

\section{Human behaviour in fire}

This section concerns human activities during a fire, including asleep/ awake status, awareness of the presence of a fire, main activities during a fire, and methods of extinguishment, as shown in Table 2.

Asleep versus awake. Information concerning asleep versus awake status was available for 157 hosts. Three quarters of survived hosts were awake and unimpaired at ignition, and one quarter reported that they were asleep when the fire started.

Awareness of a fire. Multiple methods of being alerted to the presence of a fire were recorded. In nearly a quarter of cases the fire cue that first alerted a fire survivor was the smell of smoke, followed by the sight of flames/ glow (of fire). Other often-reported fire cues included that the person heard sounds from the fire, saw smoke, or heard an activated smoke alarm.

Host's main actions during a fire. Two main actions were recorded for a host. Over one third of hosts attempted to extinguish the fire or called fire brigade, a little under one third tried to alert others, and a minority of hosts investigated fires, in particular fires where there was no human involvement in ignition. Other activities include that hosts attempted to collect personal belongs or pets, attempted to rescue others, or disconnected the power sources. Notably, only a minority behaved 'irrationally' in the face of a fire. Irrational behaviour refers to situations where a host's behaviour was so concerning to others at the scene that some restraining behaviour was warranted. One example is a 24 year old female who accidentally ignited the outside furniture with a discarded cigarette. During the fire, she was desperate to find her dog and ran across the fire area several times and eventually she was restrained by the fire brigade. As another example, when the fire was out of control, a mother was determined to put the fire out by herself as she did not have insurance and did not want her house to burn down. At the end, her friend had to hit her and drag her out of the house as she would not listen.

Methods of extinguishment. In one third of fires, there was no attempt made to extinguish the fire at the time of ignition. Nearly one third of hosts, and over one third of people on premises other than the interviewee, attempted to extinguish the fire. Where an attempt was made to extinguish the fire, one third of cases used water from a container, another quarter attempted smothering, a quarter used a garden hose, and one out of ten used a fire extinguisher. About $6.3 \%$ of households adopted multiple methods to extinguish fires. The majority of fires were extinguished by the fire brigade and a minority selfextinguished.

\section{Fire agent}

As shown in Table 3, electrical failure and unattended cooking were the leading causes of survived accidental residential fires, followed by combustibles too close to heat, lack of maintenance, and children playing with ignition sources. Only five fires were caused by discarded cigarettes. Fires caused by electrical failure include any mechanical failure/ fault/ malfunction detected or reported in electrical or ignition system, such as electrical distribution equipment (i.e., extension cords or plugs) or electronic equipment (i.e., TV, extraction fan, air condition unit). In terms of cooking fires, unattended cooking predominated. Other cooking-related scenarios include combustibles too close to heat (i.e., paper towel), careless cooking behaviours (i.e., food left burning in the rubbish bin or fry pan), cooking appliances (i.e., stove) unintentionally being turned on and not turned off, and lack of maintenance of appliances (heavy grease left in the grill or oven). 
There was no appliance involved in the ignition for nearly a quarter of survived fires. When an appliance was involved, the stove predominated, followed by heating-related appliances, electrical distribution equipment, extraction fan, and lamp/ light globe. Other appliances included air conditioning units, portable cookers, electrical distribution equipment and TVs.

Plastic predominated in the type of materials ignited, followed by fabric/ fibre/ finished goods, cooking oil, and wood. Heat from gas fuelled equipment, unspecified short circuit arc, and from properly and improperly operating electrical equipment were the main forms of heat ignition. Not surprising, cooking material was a leading form of material ignited, followed by appliances and electrical wiring.

\section{Environment-related factors}

Environment-related factors covers information related to characteristics of a dwelling, season and time of a fire, room of fire origin, presence and performance of fire safety equipment as well as fire and smoke damage. Table 4 shows the frequencies of variables within the context of environment.

Characteristics of a dwelling. An overwhelming majority of properties were one or two family dwellings, followed by apartments and units. Over half of properties were owned by the host or host's relatives, followed by rental ones. One out of twenty properties was in a state of disrepair and only a small amount of buildings were either moderately or severely cluttered.

Season and time of a fire. The distribution of survived accidental residential fires was relatively even across the different seasons. The time of fires was concentrated in the two periods covering noon to midnight and a further investigation shows that peaks were evident at the usual cooking times for lunch (12:00pm-1:59pm, 13.2\%, 16/121) and dinner (7pm-8:59pm, 16.5\%, 20/121).

Room of fire origin (RFO). In line with the ignition factor, the kitchen was the leading room of fire origin, followed by the bedroom, ceiling and roof space, toilet/ bathroom, garage, lounge room, and laundry.

Fire safety equipment. The data shows that $88.5 \%(162 / 183)$ of survivor households interviewed were known to have a smoke alarm present and over two thirds of alarms were activated at the time of fire. There were an additional six fire incidents where it was reported that the smoke alarm had been disconnected (i.e., battery removed). In terms of other fire safety equipment, only $7.1 \%(13 / 183)$ of households where a fire occurred reported that a sprinkler was present; these 13 fires however, were reported to be too small to be detected by a sprinkler. Over two thirds of households had no additional (i.e. additional to smoke alarms and sprinklers) fire safety equipment present. Interestingly, where additional fire safety equipment was available, it was not always used. A fire extinguisher was available in 30 fires, but only used in $13(43.3 \%, 13 / 30)$, while a fire blanket was present in 22 fires, but only used in less than a third $(31.8 \%, 7 / 22)$.

Fire and smoke damage. The extent of fire damage was confined to partial area of RFO for a less than half of the households and one fifth properties encountered fire damage to the entire RFO and minor damage to other rooms. By contrast, smoke damage to the entire RFO and minor smoke damage to other rooms occurred in near half of the households, followed by damage to entire RFO and entire house. 
Table 1. Frequency distributions of human-related variables from survived accidental residential fires

\begin{tabular}{|c|c|c|}
\hline Human-related variables & $\begin{array}{c}\text { Percentage } \\
(\%)\end{array}$ & $\begin{array}{c}\text { Number } \\
(n)\end{array}$ \\
\hline \multicolumn{3}{|l|}{ Age $(n=183)$} \\
\hline - Under 18 & 9.8 & 18 \\
\hline - $18-59$ & 72.7 & 133 \\
\hline - $60+$ & 17.5 & 32 \\
\hline \multicolumn{3}{|l|}{$\operatorname{Sex}(n=183)$} \\
\hline - Male & 45.9 & 84 \\
\hline - Female & 54.1 & 99 \\
\hline \multicolumn{3}{|l|}{ Country born $(n=160)$} \\
\hline - Australia & 68.1 & 109 \\
\hline - Overseas & 31.9 & 51 \\
\hline \multicolumn{3}{|l|}{ Living arrangement $(n=179)$} \\
\hline - With family & 82.7 & 148 \\
\hline - With others & 6.7 & 12 \\
\hline - Alone & 10.6 & 19 \\
\hline \multicolumn{3}{|l|}{ Mental illness $(n=166)$} \\
\hline - Yes & 16.3 & 27 \\
\hline - $\mathrm{No}$ & 83.7 & 139 \\
\hline \multicolumn{3}{|l|}{ Physical illness $(n=165)$} \\
\hline - Yes & 15.8 & 26 \\
\hline - $\mathrm{No}$ & 84.2 & 139 \\
\hline \multicolumn{3}{|l|}{ Current smoker $(n=170)$} \\
\hline - Yes & 26.4 & 45 \\
\hline - No & 73.6 & 125 \\
\hline \multicolumn{3}{|l|}{ Drug use $(n=156)$} \\
\hline - Yes & 1.9 & 3 \\
\hline - $\mathrm{No}$ & 98.1 & 153 \\
\hline \multicolumn{3}{|l|}{ Alcohol use $(n=156)$} \\
\hline - Yes & 10.9 & 17 \\
\hline - $\mathrm{No}$ & 89.1 & 139 \\
\hline \multicolumn{3}{|l|}{ Previous fire experience $(n=153)$} \\
\hline - Yes & 81.7 & 125 \\
\hline - $\mathrm{No}$ & 18.3 & 28 \\
\hline \multicolumn{3}{|l|}{ Fire safe knowledge $(n=153)$} \\
\hline - No pre-existing knowledge & 7.2 & 11 \\
\hline - Basic/ general knowledge & 69.9 & 107 \\
\hline - Some specific learning & 21.7 & 33 \\
\hline - Technical/ formal training & 1.2 & 2 \\
\hline
\end{tabular}


Table 2. Human behaviour in fire

\begin{tabular}{|c|c|c|}
\hline Human behaviour-related variables & $\begin{array}{c}\text { Percentage } \\
(\%)\end{array}$ & $\begin{array}{c}\text { Number } \\
(n)\end{array}$ \\
\hline \multicolumn{3}{|l|}{ Asleep/ awake status $(n=157)$} \\
\hline - Asleep & 24.8 & 39 \\
\hline - Awake & 75.2 & 118 \\
\hline \multicolumn{3}{|l|}{ Awareness of a fire $(n=183)$} \\
\hline - Smelt smoke & 23.5 & 43 \\
\hline - Saw flames/glow (of fire) & 19.1 & 35 \\
\hline - Heard fire/ explosion & 15.8 & 29 \\
\hline - Saw smoke & 12.6 & 23 \\
\hline - Smoke alarm & 12.0 & 22 \\
\hline - Fire started by own action & 6.7 & 12 \\
\hline - Heard voice/ screams & 2.7 & 5 \\
\hline - Multiple & 7.6 & 14 \\
\hline \multicolumn{3}{|l|}{ Main activities during fire $(n=180)^{\text {a }}$} \\
\hline - Call the fire brigade & 40.0 & 72 \\
\hline - Attempted to extinguish fire & 38.9 & 70 \\
\hline - Trying alert others & 29.4 & 53 \\
\hline - Investigating fire & 15.0 & 27 \\
\hline - Attempted to collect personal belongs or pets & 11.1 & 20 \\
\hline - Attempted to rescue others & 9.4 & 17 \\
\hline - Extinguished the fire & 8.9 & 16 \\
\hline - Irrational action ${ }^{\mathrm{b}}$ & 5.0 & 9 \\
\hline - Disconnected power source & 4.4 & 8 \\
\hline \multicolumn{3}{|l|}{ Who attempted to extinguish fire $(n=183)$} \\
\hline - No one attempted & 33.8 & 62 \\
\hline - Person on premises at time of ignition & 32.2 & 59 \\
\hline - Interviewee & 27.9 & 51 \\
\hline - Person off premises at time of ignition & 6.0 & 11 \\
\hline \multicolumn{3}{|l|}{ How attempted to extinguish fire $(n=120)$} \\
\hline - Water from container & 33.3 & 40 \\
\hline - Smothering & 25.8 & 31 \\
\hline - Garden hose & 23.3 & 28 \\
\hline - Fire extinguisher & 10.8 & 13 \\
\hline - Multiple & 6.7 & 8 \\
\hline \multicolumn{3}{|l|}{ Who extinguished the fire $(n=183)$} \\
\hline - Fire brigade & 77.6 & 142 \\
\hline - Person on premises & 10.3 & 19 \\
\hline - Person off premises & 3.8 & 7 \\
\hline - Interviewee & 5.5 & 10 \\
\hline - Fire self-extinguished & 2.7 & 5 \\
\hline
\end{tabular}

Note. andicates the cumulative percentage is not $100 \%$ as two main activities were documented.

${ }^{\mathrm{b}}$ Irrational behaviour refers to situations where a host's behaviour was so concerning to others at the scene that some restraining behaviour was warranted. 
Table 3 Frequency distribution of fire agent from survived accidental residential fires

\begin{tabular}{|c|c|c|}
\hline Fire agent-related variables & $\begin{array}{l}\text { Percentage } \\
(\%)\end{array}$ & $\begin{array}{c}\text { Number } \\
(n)\end{array}$ \\
\hline \multicolumn{3}{|l|}{ Ignition factor $(n=175)^{\mathrm{a}}$} \\
\hline - Electrical failure & 35.4 & 62 \\
\hline - Unattended cooking & 18.9 & 33 \\
\hline - Combustibles too close to heat & 16.0 & 28 \\
\hline - Lack of maintenance/ worn out & 8.0 & 14 \\
\hline - Children playing with ignition sources & 6.9 & 12 \\
\hline - Cooking other & 6.3 & 11 \\
\hline - Overloaded & 3.4 & 6 \\
\hline - Discarded cigarettes & 2.9 & 5 \\
\hline - Others (i.e., open fire, design fault, lightning, improper start up/ shut down) & 6.9 & 12 \\
\hline \multicolumn{3}{|l|}{ Appliances involved $(n=177)$} \\
\hline - No appliance involved & 22.0 & 39 \\
\hline - Stove & 22.6 & 40 \\
\hline - Heating unit (i.e., central, fixed, portable, indoor fireplace) & 9.6 & 17 \\
\hline - Electrical distribution equipment, fixed wiring, cord, plug, charger & 9.6 & 17 \\
\hline - Extraction fan & 6.2 & 11 \\
\hline - Lamp/ light globe & 8.5 & 10 \\
\hline - Portable cooker & 4.0 & 7 \\
\hline - Oven & 3.3 & 6 \\
\hline - Air conditioning unit & 2.8 & 5 \\
\hline - $\mathrm{TV}$ & 2.3 & 4 \\
\hline - Dryer & 1.7 & 3 \\
\hline $\begin{array}{l}\text { - Others (i.e., portable refrigeration unit, separator motor, hand tools, household } \\
\text { appliances not specified) }\end{array}$ & 7.4 & 18 \\
\hline \multicolumn{3}{|l|}{ Type of materials ignited $(n=170)$} \\
\hline - Plastic & 35.3 & 60 \\
\hline - Fabric/ fibre/ rayon / cotton/ finished goods & 17.1 & 29 \\
\hline - Cooking oil & 16.5 & 28 \\
\hline - Wood & 5.9 & 10 \\
\hline - Fat/grease & 4.7 & 8 \\
\hline - Paper & 2.9 & 5 \\
\hline - Food & 2.4 & 4 \\
\hline - Multiple & 6.5 & 11 \\
\hline - Others (i.e., natural gas, LPG gas, petrol, grain, turpentine) & 8.7 & 13 \\
\hline \multicolumn{3}{|l|}{ Form of heat ignition $(n=172)$} \\
\hline - Unspecified short circuit arc & 20.3 & 35 \\
\hline - Heat from gas fuelled equipment & 19.8 & 34 \\
\hline - Heat from properly operating electrical equipment & 18.6 & 32 \\
\hline - Heat from improperly operating electrical equipment & 12.2 & 21 \\
\hline - Candle & 5.8 & 10 \\
\hline - Lighter & 5.2 & 9 \\
\hline - Arc from faulty contact/ loose connection/ broken conductor & 4.7 & 8 \\
\hline - Heat from overloaded equipment & 4.1 & 7 \\
\hline - Heat from cigarettes or discarded smoking-related materials & 2.9 & 5 \\
\hline $\begin{array}{l}\text { - Other (i.e., liquid fuel equipment, friction, open flame/ cutting torch } \\
\text { operation) }\end{array}$ & 6.4 & 11 \\
\hline \multicolumn{3}{|l|}{ Form of material ignited $(n=175)$} \\
\hline - Cooking materials & 25.1 & 44 \\
\hline - Appliances & 18.3 & 32 \\
\hline - Electrical wiring/ cable & 9.7 & 17 \\
\hline - Bedding/ blanket/ sheet/ pillow/ mattress & 8.0 & 14 \\
\hline - Multiple & 5.7 & 10 \\
\hline - Ceiling covering/ surface & 2.9 & 5 \\
\hline - Upholstered couch/ chair & 2.9 & 5 \\
\hline - Insulation & 2.9 & 5 \\
\hline - Wearing apparel not on a person & 2.9 & 5 \\
\hline - Paper, newspaper & 2.3 & 4 \\
\hline - Others (i.e., rubbish bin, nonupholstered chair, bulk storage, gas, curtains) & 19.3 & 34 \\
\hline
\end{tabular}

Note. ${ }^{a}$ indicates the cumulative percentage is not $100 \%$ as multiple ignition factors were documented. 
Table 4 Frequency distributions of environment-related variables from survived accidental residential fires

\begin{tabular}{|c|c|c|}
\hline Environment-related variables & $\begin{array}{l}\text { Percentage } \\
(\%)\end{array}$ & $\begin{array}{c}\text { Number } \\
(n)\end{array}$ \\
\hline \multicolumn{3}{|l|}{ Type of occupancy $(n=183)$} \\
\hline - One or two family dwelling & 80.3 & 147 \\
\hline - Apartment/ unit & 10.9 & 20 \\
\hline - Tool shed & 6.0 & 11 \\
\hline - Parking garage & 1.6 & 3 \\
\hline - bungalow & 1.1 & 2 \\
\hline \multicolumn{3}{|l|}{ Property ownership $(n=182)$} \\
\hline - Owned by interviewee & 61.0 & 111 \\
\hline - Rented & 28.0 & 51 \\
\hline - Owned by relative & 3.8 & 7 \\
\hline - Public housing & 6.0 & 11 \\
\hline - Others (i.e., visitor, special accommodation) & 1.2 & 2 \\
\hline \multicolumn{3}{|l|}{ External condition to a building $(n=124)$} \\
\hline - Good overall condition & 92.7 & 115 \\
\hline - State of disrepair & 7.3 & 9 \\
\hline \multicolumn{3}{|l|}{ Internal state of a dwelling $(n=119)$} \\
\hline - Clean \& tidy & 79.0 & 94 \\
\hline - Moderately cluttered & 18.5 & 22 \\
\hline - Severely cluttered & 2.5 & 3 \\
\hline \multicolumn{3}{|l|}{ Season of a year $(n=183)$} \\
\hline - Spring (Sep., Oct., Nov.) & 25.7 & 47 \\
\hline - Summer (Dec., Jan., Feb.) & 23.0 & 42 \\
\hline - Autumn (March, April, May) & 27.3 & 50 \\
\hline - Winter (June, July, August) & 24.0 & 44 \\
\hline \multicolumn{3}{|l|}{ Time of a day $(n=121)$} \\
\hline - $24: 00-05: 59$ & 16.5 & 20 \\
\hline - $6: 00-11: 59$ & 19.8 & 24 \\
\hline - $12: 00-17: 59$ & 32.2 & 39 \\
\hline - $18: 00-23: 59$ & 31.5 & 38 \\
\hline \multicolumn{3}{|l|}{ Room of fire origin $(n=183)$} \\
\hline - Kitchen & 33.9 & 62 \\
\hline - Bedroom & 16.4 & 30 \\
\hline - Ceiling/ roof space & 9.3 & 17 \\
\hline - Toilet/ bathroom & 7.7 & 14 \\
\hline - Garage & 6.6 & 12 \\
\hline - Lounge room & 5.5 & 10 \\
\hline - Laundry & 3.3 & 6 \\
\hline - Veranda/ porch & 3.3 & 6 \\
\hline - Wall cavity/ surface & 3.3 & 6 \\
\hline $\begin{array}{l}\text { - Others (i.e., spa room, under house, backyard/ frontyard, carport, } \\
\text { rubbish area) }\end{array}$ & 10.7 & 20 \\
\hline \multicolumn{3}{|l|}{ Smoke alarm $(n=156)$} \\
\hline - No alarm present & 11.5 & 18 \\
\hline - Present and operated & 64.1 & 100 \\
\hline - Present and not operated & 24.4 & 38 \\
\hline \multicolumn{3}{|l|}{ Presence and use of additional fire safety equipment $(n=183)^{\mathrm{a}}$} \\
\hline - No additional equipment & 63.9 & 117 \\
\hline - Sprinkler & 7.1 & 13 \\
\hline - Extinguisher present/ used & $16.4 / 5.5$ & $30 / 10$ \\
\hline - Fire blanket present/ used & $12.0 / 1.1$ & $22 / 2$ \\
\hline - Bucket/ hose present/ used & $0.5 / 0.5$ & $1 / 1$ \\
\hline \multicolumn{3}{|l|}{ Fire damage from flame $(n=183)$} \\
\hline - Partial area of RFO & 41.0 & 75 \\
\hline - Entire RFO and minor damage to other rooms & 21.3 & 39 \\
\hline - Object only & 15.3 & 28 \\
\hline - Entire RFO & 9.8 & 18 \\
\hline - Entire house or apartment & 7.7 & 14 \\
\hline - Part of RFO and minor damage beyond & 2.2 & 4 \\
\hline - Moved beyond the house/ structure & 1.6 & 3 \\
\hline - Entire floor/ story (multi-storey buildings) & 1.1 & 2 \\
\hline
\end{tabular}

\footnotetext{
Smoke damage from flame $(n=180)$
} 


\begin{tabular}{lcc}
\hline Environment-related variables & $\begin{array}{c}\text { Percentage } \\
(\%)\end{array}$ & $\begin{array}{c}\text { Number } \\
(n)\end{array}$ \\
\hline - Entire RFO and minor damage to other rooms & 47.8 & 86 \\
- Entire RFO & 20.6 & 37 \\
- Entire house or apartment & 15.0 & 27 \\
- Object only & 8.3 & 15 \\
- Partial area of RFO & 6.7 & 12 \\
- Entire floor/ story (multi-storey buildings) & 0.6 & 1 \\
- Moved beyond the house/ structure & 0.6 & 1 \\
- No smoke damage & 0.6 & 1 \\
\hline
\end{tabular}

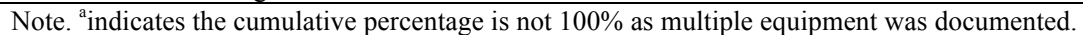

\section{DISCUSSION}

Drawing upon interviews of 183 people who had survived accidental residential fires with no serious injuries that required extended hospitalization, this study estimated the frequencies of variables associated with residential fires by adopting the basic concepts of the Haddon Matrix, human, fire agent, and environment. Six important findings emerged from the current study, giving rise to a number of implications for policy makers and practitioners, as discussed below.

First, different from findings derived from the studies of fatal fires, yet consistent with the literature on fire injuries, this study found that electrical failure and unattended cooking were the leading causes/ ignition factors of survived accidental residential fires. These cooking fires were most commonly caused by people's careless behaviours, such as leaving cooking food unattended (i.e., while sleeping), placing combustibles too close to heat, forgetting to turn off the heat, unintentionally turning on the heat, or being distracted. Smoking-related materials as the leading cause of fatal fires accounted for only $3 \%$ of survived fires examined in this study $[3,7,18,19]$. Such differences provide important insights into the possible prevention of accidental residential fires and help effectively relocate fire service resources.

Second, this study found that people's general knowledge of fire safety and awareness of unsafe fire behaviours was extremely limited. Over two thirds of people interviewed reported that they had only basic, or less, general knowledge of fire safety. Given the importance of people's careless behaviours in causing residential fires, the fact that fire safety knowledge was found to be low demonstrates the need for improved fire safety education. Much is currently known about risk factors for death in fire and this information has been used to inform existing education strategies. Although only frequencies are presented here, information from survived fires also has much to offer education programs to inform of factors that promote survivability. Ongoing work from our research team is hoping to extend knowledge surrounding these factors by comparing risk factors between survived and fatal fires.

Third, against expectation, people do not appear to learn from their mistakes; findings show that about $82 \%$ of hosts reported that this was not his or her first time to have experienced a fire incident at the time of survey. This is a shocking and potentially dangerous situation. This is in line with Barnett [20] who found that people aged over 18 years of age had approximately a $50 \%$ chance of experiencing either an attended or unattended residential fire within their adult lifetime. Future studies would benefit from conducting research on the impact of education on people who have fires repeatedly.

Fourth, risk factors that are documented elsewhere to be highly related to fire fatalities were found not to be closely related to survived fires, such as alcohol, drugs, smoking, and being asleep. In terms of fire fatalities, as mentioned earlier, smoking-related materials have been historically reported as the leading cause of home fire deaths in the U.S. [3, 18, 19]. Bruck et al [1] reported that more than half of the adults $(58 \%)$ who died in unintentional residential fires and were tested for alcohol recorded a positive BAC. Xiong et al. [21] found that a third of the adults $(24.8 \%)$ who died in accidental residential fires and were tested for drugs had consumed psychotropic and sedative drugs prior to the fire. The present less important relationships between these risk behaviours and survived fires can be partly attributed to the fact that only a small proportion of people interviewed reported that they had engaged in these risky behaviours, with most of them reporting to be awake and unimpaired at ignition. This finding, however needs to be balanced with the possibility that those people who were heavily under the influence of alcohol or other substances self-selected out of this study. 
Fifth, findings show that the majority of hosts took proactive actions when facing a fire, such as called the fire brigade, attempted to extinguish fire or collect personal belongs, tried to alert or rescue others, or disconnected power source. Notably, in one third of fires, there was no attempt made to extinguish the fire at the time of ignition (Reasons for this were not pursued in this study). Where additional fire safety equipment was available, it was not always used. A decision not to fight a fire may have been the safest and most sensible option, or may have arisen (wholly or in part) from difficulties using the fire equipment, lack of knowledge on what would be safe to do and/or psychological stress when facing the fire (i.e., disorientation, anxiety). It highlights the interesting issue of whether fire agencies should educate and encourage people to use fire extinguishment equipment to fight small fires if they believe it is safe to do so, or to focus on a message of evacuation. Sufianto and Green [22] raised the controversial idea that a society highly dependent upon the fire services only creates public opinion that the fire service is the only institution responsible for fire safety.

Finally, drawing upon the finding that electrical failure was the leading cause of survived accidental residential fires, this study suggests a need for continuous implementation of better quality and reliable electricity connection to buildings, an improvement in installation standards, and arc fault detection/protection and insulation monitoring to reduce residential fires [22, 23]. In addition to improving building safety levels, residents should be trained to check and maintain electrical equipment and connections regularly, and most importantly to avoid overloading extension cords and to discard deteriorated wiring and cord sets.

\section{LIMITATIONS}

The present findings and associated explanations should be interpreted in the light of a number of limitations. Despite a relatively low decline rate (17\%), the sample might not represent the whole population that has experienced fire incidents at the time of survey especially as there was quite a high non-contactable rate. Results might not be generalizable to people who survived residential fires and lived in other cities where demographic, socioeconomic, and ecological structures and characteristics differ. It would be interesting to compare and to determine whether the present findings hold across geographical borders. Finally, the inherent methodological limitations associated with self-reported surveys should not be taken lightly because participants might seek to present themselves in a favourable manner [24].

\section{CONCLUSION}

To our knowledge this is the first study that interviewed a relatively large number of people who have survived accidental residential fires where there was no serious injury with extended hospitalization involved. It presents important new information about the frequencies of a wide range of factors organized, using the Haddon Matrix, both thematically and across a fire event time scale. When compared with findings derived from research on fire fatalities, this study shows that survived fires share different characteristics. Future studies would benefit from utilization of the Haddon Matrix to further investigate factors associated with residential fires and direct comparisons between fatal and survived fires are encouraged.

\section{ACKNOWLEDGEMENTS}

This project was made possible by funding provided by the Melbourne Metropolitan Fire Brigade and Victorian Country Fire Authority. Special thanks to Donna Wheatley and Kirsten Meyer for their role in the data collection. 


\section{REFERENCES}

[1] Bruck, D., M. Ball, and I.R. Thomas, Fire fatality and alcohol intake: analysis of key risk factors. Journal of Study on Alcohol and Drugs, 2011. 72: p. 731-736.

[2] Romich, T.J., P.M. Horan, and C.A. Catanese, Accidental fire fatality with sustained combustion. American Journal of Forensic Medicine and Pathology, 2010. 31(3): p. 250-252.

[3] Hall, J.R., Jr., The Smoking-material fire problem, 2012, Fire Analysis and Research Division, National Fire Protection Association: Quincy, MA.

[4] Flynn, J.D., Characteristics of Home Fire Victims, 2010, Fire Analysis and Research Division, National Fire Protection Association 1 Batterymarch Park, Quincy, MA. p. 94.

[5] Brennan, P., Victims and survivors in fatal residential building fires. Fire and Materials, 1999. 23(6): p. 305-310.

[6] Runyan, C.W. and S.I. Bangdiwala, Risk factors for fatal residential fires. New England Journal of Medicine, 1992. 327(12): p. 859-863.

[7] Diekman, S., M.F. Ballesteros, and M. Ahrens, Home Fires in America: Progress and Opportunities. American Journal of Lifestyle Medicine, 2012. 6(2): p. 141-151.

[8] Haddon, W., On the escape of tigers: an ecologic note. American Journal of Public Health and Nation's Health, 1970. 60(12): p. 2229-2234.

[9] Haddon, W., Options for the prevention of motor vehicle crash injury. Israeli Medical Journal, 1980. 16: p. 45-65.

[10] Blau, G., et al., Correlates of Safety Outcomes During Patient Ambulance Transport A Partial Test of the Haddon Matrix. Journal of Allied Health, 2012. 41(3): p. 69-72.

[11] Wall, L.L., Preventing Obstetric Fistulas in Low-Resource Countries: Insights From a Haddon Matrix. Obstetrical \& Gynecological Survey, 2012. 67(2): p. 111-121.

[12] Lin, M.-R. and J.F. Kraus, A review of risk factors and patterns of motorcycle injuries. Accident Analysis \& Prevention, 2009. 41(4): p. 710-722.

[13] Rhodes, A. and S. Reinholtd, Beyond technology: a holistic approach to reducing residential fire fatalities. Australian Journal of Emergency Management, 1998. 13(1): p. 39-44.

[14] Watts, H.T., D. Bruck, and M. Ball. Examination of risk factors and mental health status in an accidental fire death population. in The 7th Asia-Oceania Fire Science and Technology Conference. 2007. Hong Kong.

[15] Zhang, G., et al., Fire safety among the elderly in Western Australia. Fire Safety Journal, 2006. 41(1): p. 57-61.

[16] Thomas, I. and D. Bruck, Smoke Alarms in Dwellings: Occupant Safety Through Timely Activation and Effective Notification, 2010, Centre for Environmental Safety and Risk Engineering Victoria University: Melbourne, Australia. Retrieved from: http://www. nfpa. org/assets/files//PDF/Proceedings/SUPDET11ThomasBruckPaper. pdf.

[17] Australian Bureau of Statistics, Australia's population by country of birth, 2011.

[18] Hall, J.R., Jr., The Smoking-material fire problem, 2007, Fire Analysis and Research Division, National Fire Protection Association: Quincy, MA.

[19] Hall, J.R., Jr., The Smoking-material fire problem, 2010, Fire Analysis and Research Division, National Fire Protection Association: Quincy, MA.

[20] Barnett, M.L., Risk factors and incidents of residential fire experiences reported retrospectively, in School of Psychology2008, Victoria University: Melbourne.

[21] Xiong, L., M. Ball, and D. Bruck, Comparative investigation of 'survival' and fatality factors in accidental residential fires, 2013, Victoria University: Melbourne. 
[22] Sufianto, H. and A. Green, Urban Fire Situation in Indonesia. Fire Technology, 2012. 48(2): p. 367-387.

[23] Shea, J.J., Identifying causes for certain types of electrically initiated fires in residential circuits. Fire and Materials, 2011. 35(1): p. 19-42.

[24] Thompson, E.R. and F.T.T. Phua, Reliability among senior managers of the Marlowe-Crowne Short-Form Social Desirability Scale. Journal of Business and Psychology, 2005. 19(4): p. 541 554. 